\title{
Study on Risk Factors, Clinical Presentation \& Operative Management of Ectopic Pregnancy
}

\author{
KAMRUN NAHAR ${ }^{1}$, TURANI TALUKDER ${ }^{2}$, SABIHA SULTANA ${ }^{3}$, MD. ANWAR HOSSAIN ${ }^{4}$
}

\begin{abstract}
:
Introduction: Ectopic pregnancy is a major clinical problem in gynaecology because it is often difficult to diagnose as the patient present in different ways. An accurate history taking and physical examination is considered to be most important in the diagnosis of ectopic pregnancy. There are two treatment options, medical or surgical. Surgical treatment is the fastest treatment for ectopic pregnancy though surgical management decreased from approximately $90 \%$ to $65 \% 1$. Surgery may be the only treatment option if there is internal bleeding. In the medical treatment group, $15 \%$ of cases were categorized as failures and required surgery ${ }^{1}$.

Objectives: This study was conducted in the department of obst and Gynae of Dhaka Medical College Hospital from January 2005 to June 2005 in an attempt to find out the risk factors of ectopic pregnancy, the way of presentation and to analyze the operative treatment of ectopic pregnancy.

Materials and Methods: A total 50 consecutive patients who were clinically suspicious of ectopic pregnancy were included in this study between January 2005 to June 2005. Patients who were clinically suspicious of EP and also supported by positive urinary pregnancy tests, beta $h C G$ and no intrauterine gestational sac in ultrasonography were included in this study. Detailed discussion about the study was done with the patient and then informed verbal consent was taken from them. Detailed history about patient profile, presenting symptoms, any risk factors and clinical examination done and the findings were recorded in the predesigned data collection sheet. Data was expressed in terms of frequencies and percentages
\end{abstract}

Results: Most of the patients were in the age group of $20-30$ years and $38 \%$ of low parity (para1).Previous miscarriage, infertility,IUCD users and PID identified as the risk factors of ectopic pregnancy $-42 \%$ patients had history of previous abortion or MR, period of infertility $22 \%$, pelvic infection $12 \%$, IUCD users $16 \%$. In this study acute abdominal pain after a short period of amenorrhoea was found to be the main symptoms in ectopic pregnancy-100\% patients were presented with lower abdominal pain, $70 \%$ with period of amenorrhea and $50 \%$ patients with per vaginal bleeding. All the patients were presented with acute condition and were surgically managed fastest treatment. At the time of operation $84 \%$ of ectopic tubal pregnancy were found ruptured, $10 \%$ were tubal abortion and $4 \%$ unruptured. Sites of ectopic pregnancy were ampullary 50\%, isthmic 20\%, fimbrial $10 \%$.

Conclusion: Most of the patient presented in acute condition with the classical features of ruptured ectopic pregnancy. Near half of the patient were in younger age group (26-30 years) having risk factors like history of previous abortion/MR 42\%, infertility 22\% use of IUCD 16\%, PID 12\%. More then three forth ( $84 \%$ ) of cases were diagnosed as ruptured ectopic during operation. Operative management was done on the basis of site of ectopic and parity of the woman

Key words: Ectopic pregnancy, risk factors, clinical presentation, salpingectomy.

Introduction:

An ectopic pregnancy (EP) in one in which the fertilized ovum become implanted in a site other than the normal uterine cavity ${ }^{2}$. More than $95 \%$ extra uterine pregnancy occur in fallopian tube ${ }^{3}$. Extra tubal sites can be the uterus itself (cervical or in a rudimentary horn of uterus), the ovary, a great rarity the broad ligament or elsewhere in the peritoneal cavity. Ectopic

1. Asstt. Prof. Obst and Gynae Shahab uddin Medical College Hospital

2. Asstt. Prof. Obst and Gynae East West Medical College and Hospital.

3. Registrar Obst and Gynae Delta Medical College and Hospital

4. Ex Prof. Obst and Gynae, BSMMU. 
pregnancy may be bilateral and may be concurrent with an intrauterine pregnancy (Heterotrophic), but these circumstances are rare ${ }^{4}$. Ectopic pregnancy may occur any time from menarche to menopause. Incidence is maximum between the ages of 20-30 years ${ }^{5}$. The incidence of ectopic pregnancy is three times higher in women aged 35-44 years in comparison to those in the age group 15-24 years ${ }^{6}$. History of multiple lifetime sexual partner, induced abortions, pelvic inflammatory disease, smoking, $\mathrm{H}$ / O infertility, Use of IUCD, pelvic surgery significantly increase the risk of $E P^{7}$. Induced abortion and STD increase the risk 14 fold and 9 fold respectively. Previous use of IUCD increase the risk almost 4 fold, whereas the use of condoms is protective ${ }^{7}$. Erkkola and liukko suggested that PID is 5 times more common among IUCD users that in other women and this may increase the risk of EP. Incorporation of progesterone in the IUCD seems to increase the incidence of tubal pregnancy over than seen with the unmedicated devices ${ }^{8}$. Women who are subfertile are also at increased risk for an ectopic pregnancy because altered tubal integrity ( or function) contributes to both condition ${ }^{9}$. However, half of all women who receive a diagnosis of an ectopic pregnancy do not have any known risk factors ${ }^{10}$. Ectopic pregnancy is a major clinical problem in gynaecology because it is often difficult to diagnose as the patient present in different ways .

An accurate history taking and physical examination is considered to be most important in the diagnosis of ectopic pregnancy. Suspicion of ectopic pregnancy is based on the presence of one or more of the following factors- acute pelvic pain, vaginal bleeding or any risk factors for ectopic pregnancy occurring in pregnant women ${ }^{11}$. The advent of USG especially transvaginal ultrasonography(TVS), Serum progesterone, BhCG, direct vision by laparoscopy are important investigations for early diagnosis of ectopic pregnancy. In experienced hands, TVS will detect 75$80 \%$ of clinically significant tubal ectopic at the initial examination ${ }^{6}$. TVS, BhCG monitoring are the standards for evaluation of suspected ectopic pregnancy ${ }^{3}$. Over the past decade the management of ectopic pregnancy has evolved from radical operative approach ( salpingectomy) to a more conservative surgical or medical treatment ${ }^{3}$.

With improvement in diagnostic means the vast majority of ectopic pregnancy are unruptured and this has stimulated trends towards nonsurgical methods of treatment, such as systemic administration of MTX (Methotrexate) or RU 486 (Mifepristone) or local injection of MTX, Potassium Chloride $(\mathrm{KCl})$ or prostaglandin. Under laparoscopic or ultrasonographic guidance most of these conservative nonsurgical measures proved efficient in 80-90\% of appropriately selected case $\mathrm{C}^{4}$. However, surgical management is still indicated in some patients. Immediate laparotomy and clamping of the bleeding vessels may be the only means of saving the life of a moribund patient. Observational studies suggest that rates of tubal patency (60-90\%) and recurrence of ectopic pregnancy (8-15\%) are similar after medical and surgical treatment ${ }^{12}$.

\section{Methodology:}

This observational prospective study was conducted in DMCH between January 2005 to June 2005. Patients who were clinically suspicious of EP and also supported by positive urinary pregnancy tests, beta hCG and ultrasonography reveals no intrauterine gestational sac were included in this study. Patients who were clinically suspicious but laparotomy findings rulled out ectopic pregnancy were excluded from the study. Detailed discussion about the study was done with the patient and then informed verbal consent was taken from them. Detailed history about patient profile, presenting symptoms, any risk factors and clinical examination done and the findings were recorded in the predesigned data collection sheet. Data was expressed in terms of frequencies and percentages.

\section{Results:}

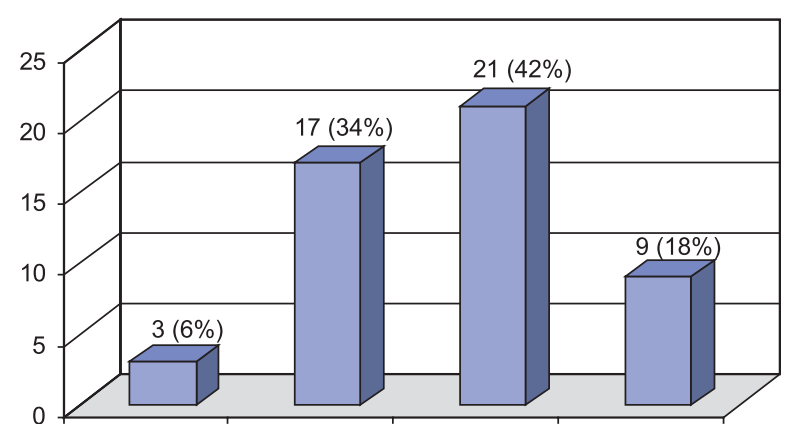

Fig.-1: Age Range in Patients with Ectopic Gestation

Fig 1 shows that 50 cases of ectopic gestations were studied, where majority 21 (42\%) of the cases were in age group (26-30) years. Less number 3 (6\%) were in age below 20 years. 
Table-I

Predisposing factors

\begin{tabular}{lcc}
\hline & No. of cases & Percent \\
\hline H/O previous abortion / MR & 21 & 42 \\
Period of infertility & 11 & 22 \\
IUCD use & 8 & 16 \\
Pelvic infection & 6 & 12 \\
H/O Appendicitis & 4 & 8 \\
H/O lower abdominal surgery & 2 & 4 \\
H/O ectopic pregnancy & 1 & 2 \\
Tuberculosis & 1 & 2 \\
\hline
\end{tabular}

Table I shows that the most of the patients 21 (42\%) had previous history of abortion / MR, period of infertility 11 (22\%), pelvic infection 6(12\%), appendicitis $4(8 \%)$, history of ectopic pregnancy 1 (2\%), tuberculosis 1 (2\%), history of abdominal surgery 2 (4\%), IUCD 8 (16\%).

Table-II

Presenting symptoms of ectopic pregnancy

\begin{tabular}{llcc}
\hline SI No. & Symptoms & No. of cases & Percent \\
\hline 1 & Abdominal pain & 50 & 100 \\
2 & Period of amenorrhoea & 35 & 70 \\
3 & P/V bleeding & 25 & 50 \\
4 & Early pregnancy symptom & 24 & 48 \\
5 & Syncopal attack & 17 & 34 \\
6 & Shock & 30 & 60 \\
\hline
\end{tabular}

Table II shows that all the cases had 50 (100\%) abdominal pain, 35 (70\%) patient had a period of amenorrhoea, 24 (48\%) had early pregnancy symptoms, P/V bleeding in 25 (50\%), syncopal attack and shock in $17(34 \%)$ and $30(60 \%)$ cases respectively.

Table-III

Signs of ectopic gestation

\begin{tabular}{lcc}
\hline SIGNS & No. of cases & Percent \\
\hline Abdominal tenderness & 50 & 100 \\
Muscle guard & 30 & 60 \\
Rebound tenderness & 3 & 6 \\
Pain on movement of cervix & 45 & 90 \\
Uterine enlargement & 25 & 50 \\
\hline
\end{tabular}

Table III shows that 50 that is $100 \%$ of the cases had abdominal tenderness, muscle guard in $60 \%$ cases, $45(90 \%)$ of the patients had pain on movement of cervix and $25(50 \%)$ of the patient had uterine enlargement.

Table-IV

Diagnostic aid for diagnosis of ectopic pregnancy

\begin{tabular}{lccc}
\hline & $\begin{array}{c}\text { No. of cases } \\
\text { diagnosed }\end{array}$ & $\begin{array}{c}\text { No. of cases } \\
\text { diagnosed } \\
\text { by other } \\
\text { methods }\end{array}$ & \\
\hline History and physical & $46(92 \%)$ & $4(8 \%)$ & 50 \\
examination. & $38(76 \%)$ & $12(24 \%)$ & 50 \\
Ultrasonography & $4(8 \%)$ & $46(92 \%)$ & 50 \\
\hline
\end{tabular}

Table IV shows that 46 (92\%) of cases were diagnosed by history, physical examination. 38 (76\%) cases diagnosed by USG, 4 (8\%) diagnosed by laparotomy.

Table-V Operative finding V.a) Site of Ectopic gestation

\begin{tabular}{lcc}
\hline Site & No. of case & Percent \\
\hline Isthmus & 10 & 20 \\
Ampulla & 25 & 50 \\
Interstial part & 4 & 8 \\
Fimbrial & 5 & 10 \\
Abdominal & 1 & 2 \\
Rudimentary horn of & 3 & 6 \\
bicornuate uterus & & \\
Ovarian & 2 & 4 \\
\hline
\end{tabular}

Table Va. shows that there were 25 (50\%) ectopic pregnancy in ampulla of fallopian tube, $10(20 \%)$ in isthmus, $5(10 \%)$ in fimbrial end of the tube. Three (6\%), 2 (4\%) were found in rudimentary horn of bicornuate uterus and ovary respectively. Only one case was found as abdominal pregnancy.

\section{V. b) Tube affected}

\begin{tabular}{lcc}
\hline Side & No. of cases & Percent \\
\hline Right & 27 & 54 \\
Left & 17 & 34 \\
\hline
\end{tabular}

Right sided tube was affected more commonly 54\% case. 


\section{V. c) Tubal status at operation}

\begin{tabular}{lcc}
\hline Status & No. of case & Percent \\
\hline Ruptured & 42 & 84 \\
unruptured & 5 & 10 \\
Tubal abortion & 5 & 10 \\
Abdominal & 1 & 2 \\
\hline
\end{tabular}

Table Vc. shows that 42 (84\%) women had ruptured fallopian tube, unruptured tube was observed in 5 (10\%) case. $10 \%$ cases were tubal abortion. There was $1(2 \%)$ case which was abdominal term pregnancy with dead baby, which was more likely to be secondary ectopic tubal pregnancy.

Table-VI

Types of operation done

\begin{tabular}{llcc}
\hline Sl. No. Types of operation & No. of case & Percent \\
\hline 1 & Unilateral salpingectomy & 29 & 58 \\
2 & $\begin{array}{l}\text { Salpingectomy with } \\
\text { contralateral tubal ligation }\end{array}$ & 12 & 24 \\
3 & Salpino-oophorectomy & 3 & 6 \\
4 & salpingotomy & 3 & 6 \\
5 & Resection of rudimentary horn & 3 & 6 \\
\hline
\end{tabular}

Table VI shows different modalities of operation done. Unilateral salpingectomy was done is 29 (58\%) cases, salpingectomy with contralateral tubectomy in 12 (24\%) cases, salpingo-oophorectomy 3 (6\%) cases, salpingotomy $3(6 \%)$ cases. Resection of rudimentary horn of bicornuate uterus was done $3(6 \%)$ cases. Salpingo-oophorectomy were done in two ruptured ovarian pregnancy and one in ruptured fimbrial pregnancy where the ovary was densly adherent to fallopian tube, which could not be separated, probably due to PID.

\section{Discussion:}

The incidence of ectopic pregnancy varies from place to place even in the same country. The incidence varies greatly through out the world, ranging from 1 in 28 to 1 in $300^{6}$. Ectopic pregnancy may occur at any age from menarche to menopause. In present study $42 \%$ of the patient were in age group 26-30 years. The youngest age group patient was $<20$ years, constitutes $3 \%$ of the case. Fernandez et al found that $65 \%$ patient range from 25-35 years, 6\% were adolescents ${ }^{13}$. A local study by Fahmida found that
$38 \%$ of the patients were in age group $26-30$ years ${ }^{14}$. This study revealed higher incidence (38\%) of ectopic pregnancy in patient with para 1 . A study by Shamima et al observed that 38\% patients had para 1-3 and $30 \%$ with para 0 . Breen found that $23.8 \%$ of patient had para 3 and $10.9 \%$ with para 0 . General symptoms as presented by the patient included the classical triad of pain, amenorrhoea and vaginal bleeding. In this study $100 \%$ patient presented with abdominal pain, $70 \%$ with period of amenorrhoea and $50 \%$ with P/V bleeding. A study of Tancer also showed that $90 \%$ of patient had abdominal pain and $63.8 \%$ abnormal vaginal bleeding ${ }^{15}$. Shamima et al observed $95 \%$ patients present with abdominal pain, $65 \%$ period of amenorrhoea and only $7 \%$ cases with irregular P/V bleeding $^{16}$.

Infertility or subfertility is a risk factor for ectopic pregnancy. In present study history of infertility was present in $22 \%$ cases. Similar findings (28\%) was found by Shamima et a1 ${ }^{16}$. History of previous induced abortion increase the risk of ectopic pregnancy 14 fold ${ }^{7}$. In current study $42 \%$ cases had previous history of menstrual regulation (MR) or abortion. The study by Fahmida observed $48 \%$ patients had previous history of MR or abortion which is almost similar to that of this study ${ }^{14}$. Use of IUCD can place a women at an increased risk of EP. In this study $16 \%$ were IUCD users. Fahmida observed that $34 \%$ patients were IUCD users ${ }^{14}$. Veldhuis HM et al observed the incidence of ectopic pregnancy in IUCD users was 6 to $11 \%$ per year ${ }^{17}$. Coste $\mathrm{J}$ et al observed the rate of contraceptive failure ectopic pregnancy mostly IUCD failure had decreased by $29 \% 18,19$. The gross disparity is due to $38 \%$ of this study population did not use any contraceptive method. $4 \%$ had history of failure of emergency contraceptive pill. The incidence of pelvic inflammatory disease (PID) has increased among the young women. In present study $12 \%$ patient had pelvic infection. Pelvic inflammatory disease, particularly due to chlamydial infection - there is a sevenfold increase in the incidence of ectopic pregnancy in women with laparoscopically proven salpingitis ${ }^{20}$. Fahmida observed $48 \%$ patients had PID. The difference is due to many women having PID are asymptomatic so the actual number of patient suffering from PID is difficult to obtain.

The mode of presentation of ectopic pregnancy may be acute, chronic or subacute. Acute presentation is usually associated with tubal rupture and massive 
intraperintoneal haemorrhage leading to acute abdominal pain and cardiovascular collapse. In this study $60 \%$ patients presented with collapse. Shamima et al observed $22 \%$ patient present with collapse and Fahmida found $94 \%$ cases of collapse ${ }^{14,16}$. The disparity reflect the amount of blood loss. Patients collapse due to hypovoluaemia and it depends upon amount of blood loss and previous haemoglobin status of the patient20

. Abdominal tenderness was observed in $100 \%$ cases in this study. Tancer et al and Fahmida found the above stated sign in $90.8 \%$ and $100 \%$ cases respectively in their series ${ }^{14,15}$. Toumivaara et al reported pain on movement of the cervix in $51 \%$ cases and abnormal uterine bleeding in $76 \%$ of their patients $^{21}$. In this study movement of the cervix produced pain in $90 \%$ of cases and abnormal uterine bleeding in $50 \%$ cases. Similar result found by Fahmida, cervical excitation test positive in $90 \%$ cases and abnormal uterine bleeding in $60 \%$ cases $^{14}$. Ultrasound examination of pelvic organs is widely used to evaluate clinically stable patient suspected of having ectopic pregnancy ${ }^{22}$. In this study $76 \%$ patients were diagnosed by ultrasonogram. Fahmida had 92\% ultrasonographically diagnosed cases. The disparity is due to most of the patient in this study were presented with acute and subacute condition and immediate laparatomy was done without waiting for ultrasonography. At the time of operation $84 \%$ of ectopic were found ruptured, $4 \%$ unruptured and $10 \%$ were aborted, there was I case of abdominal pregnancy. In the study by Fahmida there was $74 \%$ ruptured, $4 \%$ unruptured and $20 \%$ aborted. Ruptured ectopic pregnancies were observed $59.1 \%$ of cases by Beak amd $44 \%$ by Muller 23,24 . Right sided fallopian tube was affected nore commonly (54\%) than the left. Fahmida found $79 \%$ right sided tubal pregnancy ${ }^{14}$. Sites of ectopic pregnancy were ampullary $50 \%$, isthmic $20 \%$, fimbrial 10\%, $8 \%$ interstitial, $6 \%$ rudimentary horn of bicornuate uterus, $2 \%$ abdominal. A 10 years study by J. Bouyer et al found that $70 \%$ ampullary, $12 \%$ isthmic, $11 \%$ fimbrial, $2 \%$ interstitial, $3 \%$ ovarian and $1 \%$ abdominal ${ }^{25}$. Shamima et al found ampullary $64 \%$, isthmic $19 \%$, fimbrial $12 \%, 3 \%$ cornual and $2 \%$ in rudimentary horn of bicornuate uterus $^{16}$.

Regarding operative management salpingectomy was more commonly performed as because the patients came to hospital at a later stage with shock.Unilateral salpingectomy was done in $58 \%$ of the cases in this study, Salpingectomy with contralateral tubectomy in $24 \%$ cases, salpingo-oophorectomy and salpingotomy $6 \%$ in each cases, resection of rudimentary horn of bicornuate uterus in $6 \%$ cases. Type of operation varied in different studies conducted by different workers. Fahmida observed salpingectomy in 52\% cases, salpingectomy with contralateral tubectomy in $46 \%$ cases $^{14}$. Whatever may be the presentations, our ultimate goal was is to reach an early and correct diagnosis and appropriate and proper management, thereby saving the patients life as well as preserving her future fertility.

\section{Conclusion:}

Most of the patient presented in acute condition with the classical features of ruptured ectopic pregnancy. Near half of the patient were in younger age group (26 -30 years) having risk factors like history of previous abortion/MR $42 \%$, infertility $22 \%$ use of IUCD $16 \%$, PID $12 \%$. More then three forth( $84 \%$ ) of cases were diagnosed as ruptured ectopic during operation. Operative management was done on the basis of site of ectopic and parity of the woman.

\section{References:}

1. Hoover KW, Tao G, Kent CK. Trends in the diagnosis and treatment of ectopic pregnancy in the United States. Obstet Gynecol. Mar 2010;115(3):495-502.

2. Pratap Kumar, Narendra Malhotra: Ectopic pregnancy. Jeffoates principle of Gynaecology, $7^{\text {th }}$ ed. Jaypee Brothers Medical Publischers (P) Ltd. 2008; 142-159.

3. Peter S. uzelac, Sara H. Garmel. Current Obstetric and Gynaecologic Diagnosis and Treatment $10^{\text {th }}$ ed. McGraw- Hill companies 2007; 265-270.

4. S.S Ratram, K. Bhasker, S. Arul Kumaran, M. Sivasuriya. Ectopic pregnancy. Obstetrics and Gynecology for post graduates. $1^{\text {st }} \mathrm{ed}$. Orient Longman1999; 394-407.

5. D.C. Dutta. Text book of Gynaecology $3^{\text {rd }}$ ed. Calcutta: New Central book agency 2001; 176-194.

6. Dewhurst's Text book of obstetric and Gynaecology for post graduates. Edited by D. Keith Edmonds $7^{\text {th }}$ ed. Black well Publishing 2007; 106-115. 
7. Anorlu RI, Oluwole A, Abudu OO, Adebajo S. Risk factors for ectopic preg in Lagos, Nigeria. Acta Obstet Gynecoly Scand 2005; 84 (2): 184-8.

8. Luikko p, Erkkola R, Laakso L. Ectopic pregnancies during use of low dose progesterone for oral contraception 1977; 16: 575.

9. Clayton HB, Schieve LA, Peterson HB, Jamieson DJ, Reynolds MA and Wright VC. Ectopic pregnancy risk with assisted reproductive technology procedures. Obstet Gynaecol 2006; 107: 595-604.

10. ACOG Practice Bulletin no. 94: Medical management of ectopic pregnancy obstet Gynaecol 2008; 111(6) : 1479-85.

11. Fauconnier A, Mabrouk A, Heitz D, Ville Y. Ectopic Pregnancy : Interest and value of clinical examination in management policy. J Gynecol Obstet Biol Reprod (Paris). 2003; 32 (7suppl) : S18-27.

12. Mol F, Mol BV, Ankam WM, Vander Veen F, Hajenius PJ. Current evidence on surgery, systemic MTX and expectant management in the treatment of tubal ectopic pregnancy : a systemic review and metaanalysis. Hum report Update 2008; 14 : 309-19.

13. Fernandes AM, Rabeiro LP, Morases FH, Meria PC, sollero Cde A, Yamada EM. Prevalance of ectopic pregnancy liable to asurgical treatment in a public hospital from 1995 through 2000. Rev Assoc Med Bras. 2004; 50 (4): 413-6.

14. Zabin F. Clinical presentation, management and operative findings of ectopic pregnancy $\mathrm{DMCH}$, Dhaka. 1998; Dissertation.

15. Tncer ML, Delke I, Veridiano NP. A fifteen year experience with ectopic pregnancy. Surg Gynaecol Obstet 1981; 152(2): 179-82.

16. Siddiqua S, Alam MM, Khan MA T. Ectopic Pregnancy-A diagnostic dilemma. Bangladesh J obstet Gynaecol 2004;19 (1): 7-10.
17. Breen JL. A -21 years survey of 654 ectopic pregnancies. Am J obstet Gynaecol 1970; 106 (7): 1007.

18. Veldhuis HM, Vos AG, Lagro- Janssen Al. Complications of the intrauterine device in nulliparous and parous. Eur J Gen Pract 2004; 10 (3): 82-7.

19. Coste J, Bouyer J, Ughetto S, Gerbaud Z, Fernandez H, Pouly JL, Job-Spira N, Ectopic Pregnancy is again on increase. Recent trends in the incidence of ectopic pregnancies in France (1992-2002). Hum Repord 2004; 19(9): 2014-8.

20. Mukul LV. Current Management of Ectopic Pregnancy- Obstet Gynecol Clin North Am September 2007; 34(3); 403-419

21. Tuomivara L. Kanppila A. Puolakka 1. Ectopic pregnancy- an analysis of the etiology, diagnosis and treatment in 552 cases. Arch Gynaecol, 1986; 237-135.

22. Lin EP, Bhatt S, Dogra VS. Diagnostic Clues to Ectopic Pregnancy. RadioGraphics 2008; 28:1661-1671.

23. Beak P, Broslovsky, Gal et al. The role of laparoscopy in the diagnosis of ectopic pregnancy. A plea for conservation management. Int J.Gynaecol Obstet,1984; 22: 307-9.

24. Muller JE,Hacker 1, Terinde R, Kozlowski P. Change in the diagnosis and therapy of extrauterine pregnancy on special emphasis of ultrasound. Study at gynaecologic clinic of the Dusseldorf University, Gebastshilfe, frauinheilkd, 1986; 221-227.

25. Bouyer J. Coste, H. Fernandez, J.L. Pouly, N. Job-Spira. Sites of ectopic Pregnancy: a 10 years population - based study of 1800 cases. Human reproduction, 17, 2002; 3224-3230. 